\title{
Developing Peace, Economy with Probe Networks across the Taiwan Strait from the Kinmen-Xiamen Cross-Border City
}

\author{
L.Y. Hsu \\ Department of Architecture, \\ China University of Science, Technology \\ Taiwan, ROC.
}

\begin{abstract}
Kinmen and Xiamen have been the battle-front of two Chinese campaigns for many years. Yet, through recent efforts, they are becoming a cross-border city. The offering of robust, trustable social order, whose peace image can be justified through the world media, is essential. Hence, the hypercube, $Q_{n}$ with its n-bit string which has been widely applied on parallel computing in many applications is considered. Specifically, $Q_{n}$ 's derived cube-connected cycles, $\mathrm{CCC}_{\mathrm{n}}$ have been studied on that the set of the length of the cycle can be formed. That a probe network is inherently formed as this CCC graph is expected to offer incorporated detection information, and effective maintainability through the sequential Hamiltonian performance. It is expected that the information generated via probe networks can strengthen the air-sea navigation, create economic opportunities, and reduce risks. Hopefully, this cross-border governance can be a positive example for the world.
\end{abstract}

Keywords-air-sea navigation; surveillance; hamiltonian maintainability; reliability; sustainable peace

\section{INTRODUCTION}

Due to humanistic, economic developments, such as "Economic Corporation Framework Agreement (ECFA), and Xiamen Xiangan airport - the growth core of future aerotropolis [1] of two authorities, "Taiwan" (Republic of China, ROC) and "mainland China" (People's Republic of China, PRC) - at two islets originally belonging to Kinmen, the two islands - Kinmen (Fig. 1) and Xiamen - across the Xiamen bay will form a cross-border city, and have to be supported with effective, transparent mechanisms to assure the homeland security of both authorities, which had engaged many terrific fights with the other since more than eight decades ago.

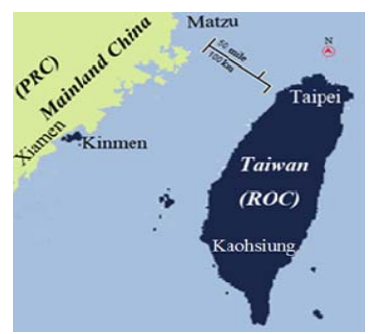

FIGURE I. KINMEN LOCATES AT THE XIAMEN BAY AND THE WEST OF THE TAIWAN STRAIT

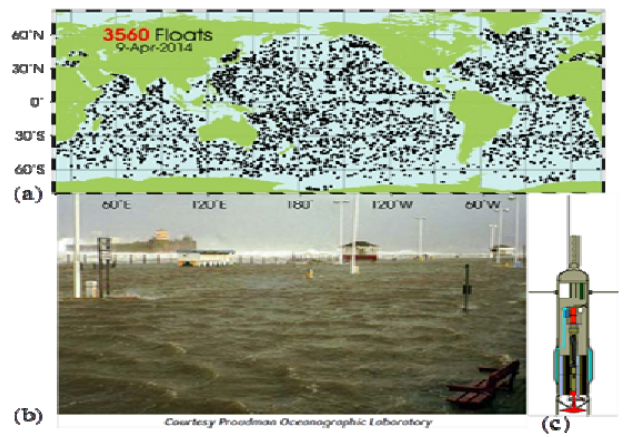

FIGURE II. OCEAN PROBE EXAMPLE - ARGO; (A). GLOBAL ALLOCATION; (B). VIEW CLOSE TO COAST; (C). ARGO'S PHYSICAL SECTION. [SOURCE: (1). WWW. UCSD.EDU (2). ARGO. JCOMMOPS.ORG (3). EN.WIKIPEDIA.ORG] [5, 8].

The link between Kinmen and Xiamen (or between Matsu and Fuzhou) is just the front part connecting both authorities. Developing the platform, including the Taiwan Strait, to enhance mutual trust as well as the positive economical development, i.e., providing the synergistic, potentially busy, air-sea routes for freight, tourism, and passengers, is needed now. Hence, a float probe based navigation/ security/ environmental protection system on the sea (Fig. 2) is referred to especially because that cheaper transportation cost and scenery via sea routes can potentially well utilize Taiwan's competitive resources [7], as well as can enhance mainland China's logistics, e.g., via a deep water harbor at the Taiwan Strait, such as Kaohsiung. Nevertheless, to count unexpected attacks cannot be neglected, for example, on logistics [9] or political manipulations due to such as sovereign concerns [for instance, see 2]. It is worthwhile to note that successful, peaceful corporation in this region will offer timeless experiences for other turbulent battlefields, borders, or regions.

If sensors are networked, dual-surveillance (two or more than two sensors as a set reasonably offer incorporated local sensing like that of a pair of eyes) allocated in complementary positions is hereby logically pondered at least for certain sensing operations. Furthermore, dual-surveillance can apply adaptable sensor allocations to respond issues related to changing environments, noise interference, and stealth technologies. 
Nevertheless, local surveillance based on single node or single probe of multiple nodes still can be arranged in the network. An effective, efficient sequential order for area inspection needs to be pondered especially if available resources are limited [10]. On networking, a Hamiltonian path (cycle) is a path (cycle) linking all nodes once. Therefore, such sequentially ordered feature is essential in communication due to confidential needs in network inspection errands. Besides, maintenance or replacement should be operated relatively easier in sparsely populated areas. Hence, tasked sensing functions are integrated in one unit (a processor node of a set of subnodes), which is called a probe-transceiver or simply a probe here.

The hypercube graph can be one of the most efficient networks for parallel computation (Fig. 3) $[12,15]$. The regular degree-3 cube-connected cycles $\left(\mathrm{CCC}_{n}\right)$ network is one of the hypercube's popular derivatives; i.e., it inherently has features of the hypercube. In the $\mathrm{CCC}_{\mathrm{n}}$ network, assuming each probetransceiver has $\mathrm{n}$ sensing operations or $\mathrm{n}$ subnodes, which can be processed and integrated in a ring or independently [10]. Hereby, $\mathrm{CCC}_{\mathrm{n}}$ is considered for application, which accommodates parallel computing of sensing functions, adaptively choosing other nodes to fulfill information transmission economically, effectively.

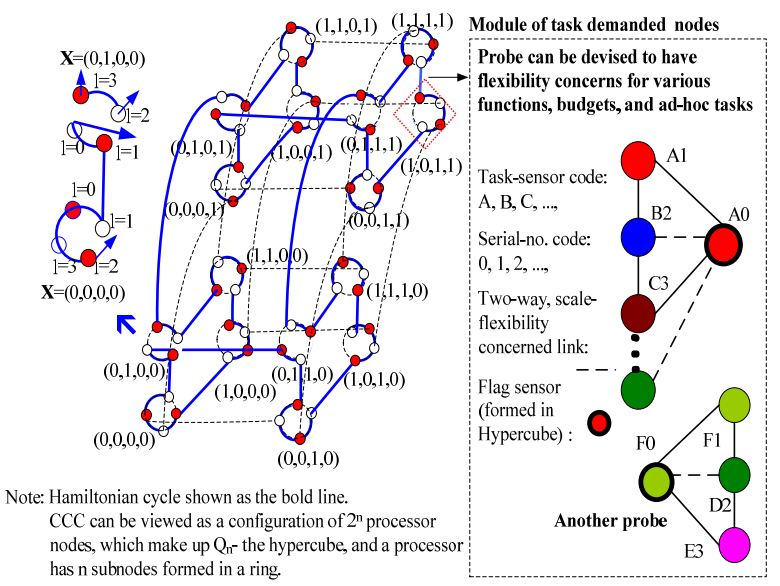

FIGURE III. PROBE CONCEPT (REFER TO THE PROTOTYPE AIMING FOR GLOBAL WARMTH MONITORING, AS THE RIGHT), RELATIONSHIP BETWEEN HYPERCUBES AND CUBE-CONNECTEDCYCLES, $\mathrm{CCC}_{4}[8]$

\section{LITERATURE REVIEW}

The examination of casino surveillance systems, where more than eight cameras may be required for a game table, helps us to recognize that the surveillance environment can be dynamic, pairing of monitoring devices can cooperatively provide better images through the operation of correlated double sampling (CDS) [3]. Due to developments of stealth technologies and terrorism [14]; hence, dual-surveillance is devised to prevent blind spots, provide fault-tolerance, and to increase capability.

Wireless technologies can affect personal welfare and global sustainability. Hence, even on the ocean [5, 11] (Fig. 2) wireless monitoring is getting more attention. Hence, features of fault-tolerance and integrity based on the dual-surveillance mechanism, as well as features of maintenance effectiveness, efficiency are considered to promote more reliability in surveillance on countering pirate ships, trafficking [4], sabotage intrusions with stealth technologies, and global environmental protection.

Wireless spoofing or interference devices, e.g., including personal privacy devices (PPD) intentionally used by truck drivers to evade legal wireless tracking in the global position system (GPS), have caused many concerns [9, 16, 17]. Hence to pervasively benefit preventing artificial or natural interference issues or to promote wireless communication integrity should be considered and is intended to support quality-assured spatial security, communication in this region.

\section{MATHEMATICAL PRELIMINARIES}

Usually, communication networks are represented by graphs in which nodes represent processors and edges represent links between processors. Let $\mathrm{G}=(\mathrm{V}, \mathrm{E})$ be a graph if $\mathrm{V}$ is a finite set and $\mathrm{E}$ is a subset of $\{(\mathrm{a}, \mathrm{b}) \mid(\mathrm{a}, \mathrm{b})$ an unordered pair of $\mathrm{V}\}$. A path is delimited by $\left(\mathrm{x}_{0}, \mathrm{x}_{1}, \mathrm{x}_{2}, \ldots \mathrm{x}_{\mathrm{n}-1}\right)$, and called a Hamiltonian path if its nodes are distinct and span V. A cycle is a path of at least three nodes such that the first node is the same as the last node. A cycle is called a Hamiltonian cycle or Hamiltonian if its nodes are distinct except for the first node and the last node, and if they span V [6].

The number of links connecting a node is called the degree; a network that regularly has fewer degrees is generally economical. Two Hamiltonian paths $\mathrm{P}_{1}=\left(\mathrm{u}_{1}, \mathrm{u}_{2}, \ldots, \mathrm{u}_{\mathrm{n}}(\mathrm{G})\right)$ and $P_{2}=\left(v_{1}, v_{2}, \ldots, v_{n}(G)\right)$ of $G$ from $u$ to $v$ are independent if $\mathrm{u}=\mathrm{u}_{1}=\mathrm{v}_{1}, \mathrm{v}=\mathrm{u}_{\mathrm{n}}(\mathrm{G})=\mathrm{v}_{\mathrm{n}}(\mathrm{G})$, and $\mathrm{u}_{\mathrm{i}} \neq \mathrm{v}_{\mathrm{i}}$, for every $1<\mathrm{i}<\mathrm{n}(\mathrm{G})$. A set of Hamiltonian paths, $\left\{\mathrm{P}_{1}, \mathrm{P}_{2}, \ldots, \mathrm{P}_{\mathrm{k}}\right\}$, of $\mathrm{G}$ from $\mathrm{u}$ to $\mathrm{v}$ is mutually independent if any two different Hamiltonian paths are independent from $\mathrm{u}$ to $\mathrm{v}$. Mutually independent Hamiltonian cycles (MIHC) can be similarly defined among cycles, and a cycle of odd length (i.e., the number of edges) can naturally have a pair of MIHC from its paired directions. The mechanism of mutually independent Hamiltonian paths (MIHP) is considered for parallel processing, and diagnosing abnormalities along the signal transmitting paths from sender nodes to the receiver nodes (Fig. 4) [9, 13].

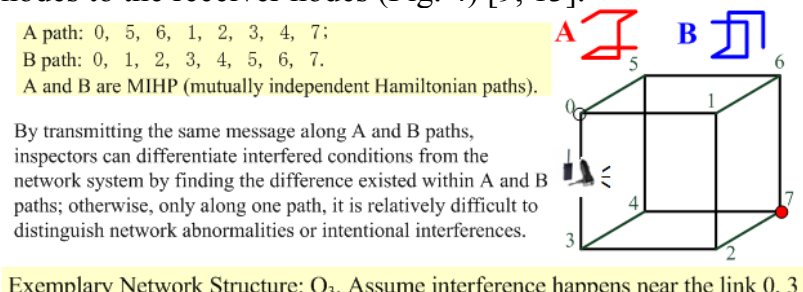

Exemplary Network Structure: $\mathrm{Q}_{3}$. Assume interference happens near the link 0, 3

\section{FIGURE IV. DIFFERENTIATE NETWORK ABNORMALITIES FROM INTENTIONAL INTERFERENCES VIA MIHP [9]}

The hypercubes (n-cube) $Q_{n}$ is defined as follows. Let node $\mathrm{u}=\mathrm{b}_{\mathrm{n}-1} \ldots \mathrm{b}_{\mathrm{i}} \ldots \mathrm{b}_{0}$ of $\mathrm{Q}_{\mathrm{n}}$ corresponds to an n-bit binary string. $\mathrm{Q}_{\mathrm{n}}$ consists of $2^{\mathrm{n}}$ nodes and $\mathrm{n} 2^{\mathrm{n}-1}$ links. For any $\mathrm{j}, 0 \leq \mathrm{j} \leq \mathrm{n}-1$, we use $(u)^{j}$ to denote the binary string $b_{n-1} \ldots b_{j} \ldots b_{0}$. (The difference between $(\mathrm{u})^{\mathrm{j}}$ and $\mathrm{u}$ is only at the j-indexed bit.) Two nodes, $\mathrm{u}$ and $\mathrm{v}$, are adjacent if and only if $\mathrm{v}=(\mathrm{u})^{\mathrm{j}}$ for some $\mathrm{j}$. A bipartite graph $\mathrm{G}=(\mathrm{V}, \mathrm{E})$ is a graph such that $\mathrm{V}=\mathrm{A} \cup \mathrm{B}$ and $\mathrm{E}$ 
is a subset of $\{(a, b) \mid a \in A$ and $b \in B\}$. The structure of bipartite graphs can be reasonably incorporated with the advantage of node fault-tolerance, and/or the performance of dualsurveillance. $Q_{n}$ is bipartite; moreover, $Q_{n}$ is node-transitive and link-transitive. $\mathrm{Q}_{\mathrm{n}}^{\mathrm{j}, \mathrm{i}}$ is a subgraph of $\mathrm{Q}_{\mathrm{n}}$ induced by $\{\mathrm{u}$ $\left.\in \mathrm{V}\left(\mathrm{Q}_{\mathrm{n}}\right) \mid(\mathrm{u})_{\mathrm{j}}=\mathrm{i}\right\}$ for $0 \leq \mathrm{j} \leq \mathrm{n}-1$ and $\mathrm{i} \in\{0,1\}$. Clearly, $\mathrm{Q}_{\mathrm{n}} \mathrm{j, \textrm {i }}$ is isomorphic to $\mathrm{Q}_{\mathrm{n}-1}$, and such an architecture can help mathematically prove scalable performances, which can be potential means for analyzing physical data (Fig. 4).

The cube-connected-cycles graph $\mathrm{CCC}_{\mathrm{n}}$ has $\mathrm{n}^{2 \mathrm{n}}$ nodes, labeled as $(1, x)$, where 1 is an integer between 0 and $n-1$, and $x$ is an $n$-bit and $x$ is the processor node with an n-bit binary string. Two vertices $(1, x)$ and $\left(l^{\prime}, y\right)$ are adjacent if and only if $\mathrm{x}=\mathrm{y}$ and $\left|1-1^{\prime}\right|=1$ or $1=1^{\prime}$ and $\mathrm{y}=(\mathrm{x})$. In the latter case, $\mathrm{x}$ and $\mathrm{y}$ only differ in the position 1 . The edges that connect $(1, x)$ to its neighbors $(1+1, \mathrm{x})$ and $(1-1, \mathrm{x})$ are called cycle-edges.

Moreover these cycle-edges form a cycle of length $n$ called a fundamental cycle defined by $\mathrm{x}$. For $\mathrm{n}=2, \mathrm{CCC}_{\mathrm{n}}$ is simply the cycle of length 8 . $\mathrm{L}(\mathrm{n})$ offers the set of all possible lengths of cycles in $\mathrm{CCC}_{\mathrm{n}}$. Shown as the recent result, $\mathrm{L}(\mathrm{n})=\{\mathrm{n}\} \mathrm{U}\{\mathrm{i} \mid \mathrm{i}$ is even and $8 \leq \mathrm{i} \leq \mathrm{n}+5$, and $\mathrm{i} \neq 10\} \cup\left\{\mathrm{i} \mid \mathrm{n}+6 \leq \mathrm{i} \leq \mathrm{n}^{2 \mathrm{n}}\right\}$ if $\mathrm{n}$ is odd; $\mathrm{L}(4)=\{4\} \mathrm{U}\{\mathrm{i} \mid \mathrm{i}$ is even and $8 \leq \mathrm{i} \leq 64\} ; \mathrm{L}(\mathrm{n})=\{\mathrm{n}\} \mathrm{U}\{\mathrm{i} \mid \mathrm{i}$ is even, and $8<i<n^{2 n}$, and $\left.i \neq 10\right\}$ if $n$ is even and $n \geq 6$ [8].

Then, each probe-transceiver is considered as a node of a hypercube, which can be organized in an ad-hoc network of $2^{n}$ sup-nodes, or $\mathrm{n}^{2 \mathrm{n}}$ nodes totally in a planned zone or selfchoosing cluster. Information sharing and interactions are functioned within reasonable scopes of wirelesstelecommunication technologies. Within that planned zone, a probe-transceiver can share data with other probe-transceivers. A probe-transceiver's architecture integrates all its nodes' operation, and then wirelessly transmits information to other areas. Hereby, $\mathrm{CCC}_{\mathrm{n}}$ is considered for application, which accommodates parallel computing of sensing functions, adaptively choosing other nodes to fulfill information transmission economically.

\section{SIGNIFICANCE IN THE APPLICATION OF CCCN AND QN}

\section{A. Adaptability in the Big-Data Robustness}

To monitor, analyze environmental changes in real-time and analyze them from historical files, the big-data technology reasonably utilizing plenty of available information sources is essential in the contemporary age [17]. Hence, the data structure of $\mathrm{CCC}_{\mathrm{n}}$ or $\mathrm{Q}_{\mathrm{n}}$ is considered important for analyzing unexpected, abnormal conditions (e.g., long foggy seasons in this area may cause to require analyzed data related to air-sea traffic management) or unique tasks if they are encountered. Naturally, other performances of $\mathrm{Q}_{\mathrm{n}}$ and $\mathrm{CCC}_{\mathrm{n}}$ can potentially increase the proposed application.

Sensor nodes within probes can be adaptively organized and to utilize specific, developed algorithms. For practical concerns, the number of sensor nodes can have flexibility - e.g., a sensor may represent two nodes. Moreover, it can benefit designing a more comprehensive information-surveillance system in an open area with rational, economical connectivity through the aforementioned research results of cycle length.

\section{B. Maintainability for Establishing Resilience}

The application area is targeted for peace developments at the front of two campaigns, which many fights have occurred before. To well justify these peaceful motives, establishing transparent information infrastructure, potentially transmitting real-time news through international media, is meaningful. In other words, such a system should have detection availability, systematic fault-tolerance (continuity) and reliable maintainability. Excluding dual-surveillance being considered for detection availability, the mathematical Hamiltonian performance, i.e., the whole nodes' sequential order, which can be processed and integrated in a ring, is one of an effective, efficient order for area inspection especially available human resources are limited.

\section{Modulability with Synergistic Effects}

In the $\mathrm{CCC}_{\mathrm{n}}$ network, assuming each probe-transceiver has $\mathrm{n}$ sensing operations or $\mathrm{n}$ subnodes, which can be processed and integrated in a ring or independently. From the concept of interconnection networks, we can also assume the network within the probe forms a sup-node, which offers comprehensive information - potentially attached with each "mathematical node" within the probe - to whole system (a float probe based navigation/ security/ environmental protection system) and is linked with two sup-nodes. Hence, the probes' communication can be simplified in general conditions, and can be analyzed systematically for reliably governing a large open, remote area.

\section{CONCLUSIONS}

Through ECFA, the construction of Xiamen Xiangan airport, and others, Kinmen and Xiamen can probably form an essential cross-border city. Cruise voyage related to both tourism and freight logistics should be considered in terms of national strategy planning, which includes an aim to well connect Kinmen as an essential part of Taiwan, R. China and benefit the integral growth, peace in Taiwan. It is hoped that Kaohsiung can get positive synergy due to the Strait's passage benefits and its port superiority. Global warming has already caused strong intention on studying the environmental physics with allocated ocean probes.

The hypercube, with its n-bit string has been widely applied on parallel computing for many fields. $Q_{n}$ 's derived cube-connected cycles, $\mathrm{CCC}_{\mathrm{n}}$ have been well studied on that the set of the length of the cycle can be formed. That a probe network is inherently formed as the cube-connected cycle graph is expected to offer incorporated detection information, and effective maintainability through the performance of sequential Hamiltonian order and others.

It is expected that the information generated via probe networks can strengthen the navigation for the ship and the plane. In other words, by participating in establishing the ocean probe platform at the Taiwan Strait can positively create economic opportunities, and reduce risks - probably due to transportation accidents or terrorism.

\section{ACKNOWLEDGMENT}

The author would present his thankfulness to the support of ucplyh00 from National Center for High Performance 
Computing, ROC, and many positive discussions, suggestions from colleagues.

\section{REFERENCES}

[1] Ashford, N. Mumayiz, S. and Wright, P. Airport Engineering: Planning, Design, and Development of 21 st Century Airports, New York: John Wiley, 673-681, 2011.

[2] Bashar, K. Senkaku dispute escalates, the Sundaily, www.thesundaily.my/node/236707, Jan. 06, 2014 [retrieved on Oct. 10, 2014].

[3] Damjanovski, V. CCTV networking and digital technology, Amsterdam: Elsevier, 159-168, 2005.

[4] Fritteli, J. F. Port and maritime security, Hauppauge, New York: Nova Science, 17-19, 2008.

[5] Getter, R. Argo will explore our climate's future - thousands of probes will serve as underwater weather stations, http://www.rgetter.com/pages/ns_articles/argo /argo.htm [retrieved on Oct. 10, 2014].

[6] Hsu, L.-H. and Lin, C.-K. Graph theory and interconnection networks, New York: CRC Press, 1-20, 2008.

[7] Hsu, L.-Y. Sustaining Taiwan from rethinking D'aiwan in different living approaches, Proceedings of the 7 th Conference of International Forum on Urbanism (IFoU), Creative Renaissance (eds: F.-T. Lin and J. Rosemann) 187-196, Tainan: Nat'l Cheng Kung University, Taiwan, 2013a.

[8] Hsu, L.-Y. Developing probe networks with cube-connected-cycles and parallelism, J. Northerthern University - Natural Science, 34(S1). 340-344, Shenyang, 2013b.

[9] Hsu, L.-Y. and Yuan, M.-S. Informing vehicle architectures with diagnosability and security, Information Engineering, 2(4). 61-67, Seipub, pdf file on http://www.academia.edu/8043042/Informing_Vehicle

Archi tectures_with_Diagnosability_and_Security [retrieved on Oct. 10, 2014] 2013.

[10] Knezevic J. Systems maintainability - analysis, engineering and management. London: Chapman Hall, 11, 221, 1997.

[11] Knox R and Douglass D. Recent energy balance of earth. International Journal of Geosciences, 1(1): 99-101, 2010.

[12] Leighton F. Introduction to parallel algorithms and architectures: arrays. trees. Hypercubes, Burlington, MA: Morgan Kaufmann, 389-392, 1992.

[13] Li, F. Interference cancellation using space-time processing and precoding design, New York: Springer-Verlag, Ch.1, 2013.

[14] Mansfeld, Y. and Pizam, A. (2006) Tourism, security, and safety from theory to practice, Burlington, MA: Elsevier BH, 2-5, 2006.

[15] Parhami B. Introduction to parallel processing: algorithms and architectures, New York: Kluwer, 261-310, 2002.

[16] (PNT) National Space-Based Positioning, Navigation, and Timing Advisory Board. National PNT advisory board comments on jamming the global positioning system - a national security threat: recent events and potential cures, Nov. 4, http://www.glarrnav.org/pdfs/interference_to_gps _v101_3_.pdf [retrieved on Oct. 10, 2014] 2010.

[17] Pullen, S. and Gao, G. GNSS Jamming in the name of privacy: potential threat to GPS aviation, InsideGNSS - engineering solutions from the global navigation satellite system community, March/April, 34-43, pdf file on http://Www.insidegnss.com/node/2976 [retrieved on Oct. 10, 2014] 2012.

[18] Zadronzy, P. and Kodali, R. Big data analytics using Splunk, New York: Apress, Ch.1, 2013 